Article

\title{
Inhibition of Advanced Glycation End-Product Formation and Antioxidant Activity by Extracts and Polyphenols from Scutellaria alpina L. and S. altissima L.
}

\author{
Izabela Grzegorczyk-Karolak ${ }^{1, *}$, Krzysztof Gołąb ${ }^{2}$, Jakub Gburek ${ }^{2}$, Halina Wysokińska ${ }^{1}$ and \\ Adam Matkowski ${ }^{3}$ \\ 1 Department of Biology and Pharmaceutical Botany, Medical University of Lodz, ul. Muszynskiego 1, \\ Lodz 90-151, Poland; halina.wysokinska@umed.lodz.pl \\ 2 Department of Pharmaceutical Biochemistry, Wroclaw Medical University, ul. Borowska 211A, \\ Wroclaw 50-556, Poland; krzysztof.golab@umed.wroc.pl (K.G.); jakub.gburek@umed.wroc.pl (J.G.) \\ 3 Department of Biology and Pharmaceutical Botany, Wroclaw Medical University, ul. Borowska 211, \\ Wroclaw 50-556, Poland; bbsekret@umed.wroc.pl \\ * Correspondence: izabela.grzegorczyk@umed.lodz.pl; Tel./Fax: +48-42-677-91-60
}

Academic Editor: Isabel C. F. R. Ferreira

Received: 24 April 2016; Accepted: 1 June 2016; Published: 14 June 2016

\begin{abstract}
Methanolic extracts from the aerial parts and roots of two Scutellaria species, S. alpina and S. altissima, and five polyphenols from these plants demonstrated a significant ability to inhibit the formation of advanced glycation end-products (AGE) in vitro. S. alpina, which is richer in polyphenolic compounds, had strong antiglycation properties. These extracts demonstrated also high activity in the FRAP (ferric-reducing antioxidant power), antiradical (DPPH) and lipid peroxidation inhibition assays. Among the pure compounds, baicalin was the strongest glycation inhibitor $(90.4 \%$ inhibition at $100 \mu \mathrm{g} / \mathrm{mL}$ ), followed by luteolin (85.4\%). Two other flavone glycosides had about half of this activity. Verbascoside was similar to the reference drug aminoguanidine $(71.2 \%$ and $75.9 \%$, respectively). The strong correlation observed between AGE inhibition and total flavonoid content indicated that flavonoids contribute significantly to antiglycation properties. A positive correlation was also observed between antiglycative and antioxidant activities. The studied skullcap species can be considered as a potential source of therapeutic agents for hyperglycemia-related disorders.
\end{abstract}

Keywords: advanced glycation end products; flavonoids; antioxidants; Scutellaria alpina; Scutellaria altissima

\section{Introduction}

Glycation is the non-enzymatic formation of adducts between amino groups and the carbonyl groups of reducing sugars. In the early stage, a sugar reacts with the free amino group of a biological amine to form an unstable compound, a Schiff base, which then undergoes rearrangement to form more stable Amadori products (early glycation products). These Amadori products degrade to form a variety of reactive dicarbonyl compounds, such as glyoxal, methyl glyoxal and deoxyglucosones, which are much more reactive than the initial sugars. In the late stage of glycation, due to dehydration, oxidation and cyclization reactions, irreversible compounds, called advanced glycation end products (AGEs), are formed [1].

The accumulation of protein glycation products in living organisms leads to structural and functional modifications of tissue proteins. Via receptor-dependent and direct pathways, AGEs promote the initiation and development of diabetic complications, which are categorized as macro- and micro-vascular lesions. The most common microvascular complications include 
neuropathy, nephropathy, retinopathy and cataract, while the macrovascular complications are atherosclerosis, coronary heart disease and cerebrovascular disease [2-4]. Although hyperglycemia plays a key role in the pathogenesis of diabetic complications, the formation of AGE progressively increases with normal aging.

Traditionally, plant extracts have been used in the management of diabetes. Numerous studies have shown the effectiveness of crude plant extracts or their bioactive compounds in lowering blood glucose levels [5]. The inhibition of advanced glycation end products (AGEs) is yet another mode of diabetes treatment not dependent on the control of blood glucose level and would be useful in the prevention or mitigation of certain diabetic complications [6,7]. AGE inhibitors are divided into three classes: carbonyl-trapping agents, which attenuate carbonyl stress; metal ion chelators, which suppress glycoxidation; and cross-link breakers, which reverse AGE cross-linking [8]. Many synthetic inhibitors of AGE formation are not in clinical use, due to unsatisfactory safety profiles. However, the phenolic phytochemicals present in fruits, herbs and vegetables, besides being strong antioxidants and glycation inhibitors, are usually safe for human consumption $[9,10]$.

Several species of skullcap (genus Scutellaria) have been used in folk medicine for thousands of years. They have been traditionally used as anti-inflammatory, antiviral, sedative, antithrombotic and antioxidant remedies, primarily in East Asia. Skullcaps were prepared as a tincture alone and with other herbs in numerous prescriptions, such as: Huangqui Baizhi San, Huangqui Yin, Huangqui Tang, Huangqui Gao. The tea industry used S. baicalensis also for making tea and in the food industry as a flavoring agent for stewing meat and fish [11]. Some species and the phenolic compounds isolated from them continue to be used also in conventional medicine [11]. One species, S. baicalensis, is listed in European and Chinese pharmacopoeias.

The two species chosen for our study, S. altissima L. and S. alpina L., are native to some regions in Eastern and Southern Europe and are not fully exploited as official medicinal herbs. However, they are known to contain substantial amounts of potentially highly active polyphenols. At present, the only information on antiglycation activity is available for the well-known traditional Chinese herb Scutellariae baicalensis radix [12]. The two major flavones present in S. baicalensis, baicalin and wogonoside, are also present in both studied species [13]. The present paper reports the in vitro antiglycative and antioxidant activity of extracts from the roots and aerial parts of S. alpina and S. altissima grown in a botanical garden in Poland. It also evaluates the inhibitory activity of the AGE formation of compounds identified as major bioactive metabolites from the analyzed extracts (baicalin, wogonoside, luteolin, luteolin-7-glucoside and verbascoside). They were identified in the Scutellaria samples by comparing their retention times, UV spectra and MS data with those of the standards. LC-MS/MS (liquid chromatography-mass spectrometry) data of the compounds has been published previously $[14,15]$ (Tables S1 and S2, Supplementary Materials).

\section{Results}

In order to fully characterize the antioxidant properties of Scutellaria plants, three in vitro tests based on different mechanisms were used in the study (Table 1).

The FRAP assay measures the ability to reduce iron ions $\left(\mathrm{Fe}^{3+}\right.$ to $\left.\mathrm{Fe}^{2+}\right)$. The strongest reducing ability was observed for the root extract of S. alpina $(717.6 \mu \mathrm{M} \mathrm{Fe}(\mathrm{II}) / \mathrm{g}$ dry extract), which was significantly higher than shoot extract $(669.6 \mu \mathrm{M} \mathrm{Fe}(\mathrm{II}) / \mathrm{g}$ dry extract) and almost twice as high as in extracts from S. altissima (369.4 and $391.7 \mu \mathrm{M} \mathrm{Fe}(\mathrm{II}) / \mathrm{g}$ dry extract), for roots and shoots, respectively).

In the DPPH anti-free radical assay, the extract from S. alpina roots again was the most efficient, with the lowest $\mathrm{EC}_{50}$ of $69 \mu \mathrm{g} / \mathrm{mL}$. The values were found to be only a little higher in the shoots of this species $(71.3 \mu \mathrm{g} / \mathrm{mL})$, and the difference was not statistically significant. Both S. altissima extracts had significantly lower abilities to scavenge free radicals $\left(\mathrm{EC}_{50}=82.9\right.$ and $102.7 \mu \mathrm{g} / \mathrm{mL}$, for roots and shoots, respectively).

The inhibition of linoleic acid peroxidation (LPO) by Scutellaria plant extracts was assayed by the TBARS test. Similar to the DPPH and FRAP assays, the best inhibition ability was observed for the 
S. alpina root extract. The extract inhibited linoleic acid peroxidation by more than $60 \%$. The shoots of S. altissima showed the weakest activity, with an inhibitory effect of $30 \%$.

Table 1. Total phenolic compounds and antioxidant activities of S. altissima and S. alpina extracts determined by reducing power (FRAP), the DPPH scavenging assay and inhibition of linoleic acid peroxidation (TBARS detection).

\begin{tabular}{ccccc}
\hline Plant Material & $\begin{array}{c}\text { Total Flavonoid } \\
\text { Content }^{*}\end{array}$ & $\begin{array}{c}\text { FRAP } \mu \text { M Fe(II)/g } \\
\text { Dry Extract }\end{array}$ & $\begin{array}{c}\text { DPPH Assay } \\
\text { EC }_{\mathbf{5 0}}(\boldsymbol{\mu g} / \mathbf{m L}) * *\end{array}$ & $\begin{array}{c}\text { \% Inhibition Lipid } \\
\text { Peroxidation }\end{array}$ \\
\hline S. altissima shoots & $14.01 \pm 0.15^{\mathrm{a}}$ & $391.66 \pm 6.13^{\mathrm{c}}$ & $102.68 \pm 3.91^{\mathrm{d}}$ & $29.76 \pm 1.19^{\mathrm{d}}$ \\
S. altissima roots & $13.83 \pm 0.13^{\mathrm{a}}$ & $368.37 \pm 7.23^{\mathrm{d}}$ & $82.94 \pm 0.45^{\mathrm{c}}$ & $36.90 \pm 0.84^{\mathrm{c}}$ \\
S. alpina shoots & $25.05 \pm 0.43^{\mathrm{b}}$ & $669.63 \pm 11.07^{\mathrm{b}}$ & $71.26 \pm 0.34^{\mathrm{b}}$ & $51.85 \pm 3.75^{\mathrm{b}}$ \\
S. alpina roots & $27.16 \pm 0.87^{\mathrm{b}}$ & $717.60 \pm 1.35^{\mathrm{a}}$ & $68.98 \pm 0.30^{\mathrm{a}}$ & $60.32^{\mathrm{b}} \pm 1.61^{\mathrm{a}}$ \\
\hline
\end{tabular}

${ }^{*}$ Expressed as quercetin equivalents (mg per gram of dry extract). ${ }^{* *} \mathrm{EC}_{50}$, the concentration of the sample $(\mu \mathrm{g} / \mathrm{mL})$ showing $50 \%$ of maximal radical scavenging activity. The means with the same letter for the same assay do not differ significantly according to the Kruskal-Wallis test $(p \leqslant 0.05)$. The values are the means of six replicates \pm SE.

The ability of Scutellaria altissima and S. alpina extracts to inhibit AGE formation was evaluated using the antiglycation assay, in which bovine serum albumin served as the model protein and glucose and fructose as the glycating agents. The formation of AGEs was assessed by monitoring the production of fluorescent products at excitation and emission maxima of $335 \mathrm{~nm}$ and $385 \mathrm{~nm}$, respectively [1]. Higher wavelength settings $(370 / 440 \mathrm{~nm})$ are unsuitable for Scutellaria extracts, due to the strong interference from autofluorescence. All tested extracts inhibited AGE formation in a dose-dependent manner. In general, S. alpina extracts showed a higher inhibitory effect than the extracts of S. altissima. Both S. alpina extracts presented more than $70 \%$ inhibition of AGE formation at a concentration of $100 \mu \mathrm{g} / \mathrm{mL}$. These extracts exhibited $\mathrm{IC}_{50}$ values of about $60 \mu \mathrm{g} / \mathrm{mL}(57.9 \mu \mathrm{g} / \mathrm{mL}$ for shoots and $61.4 \mu \mathrm{g} / \mathrm{mL}$ for roots). S. altissima extracts showed much lower activity ( $\mathrm{IC}_{50} 140-180 \mu \mathrm{g} / \mathrm{mL}$ ) (Figure 1).

A

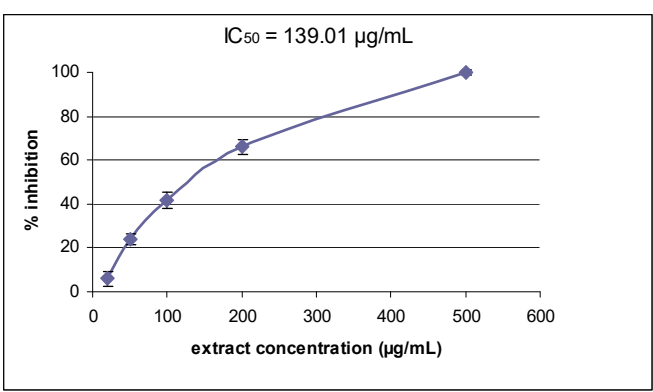

C

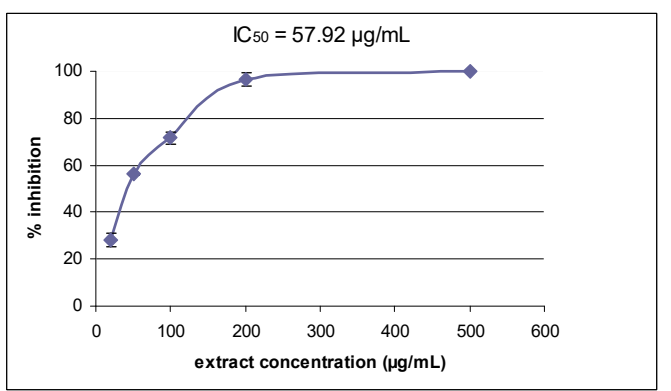

B

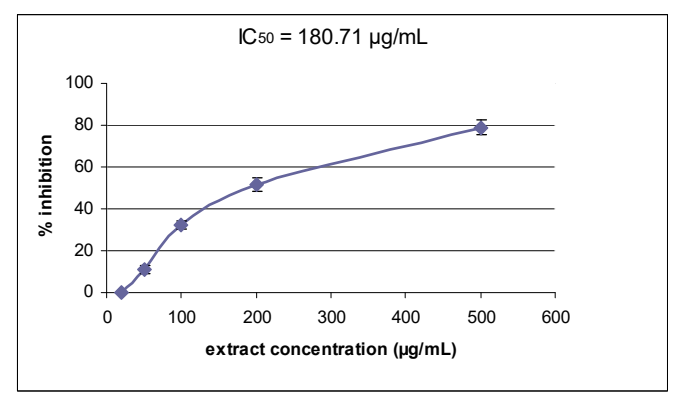

D

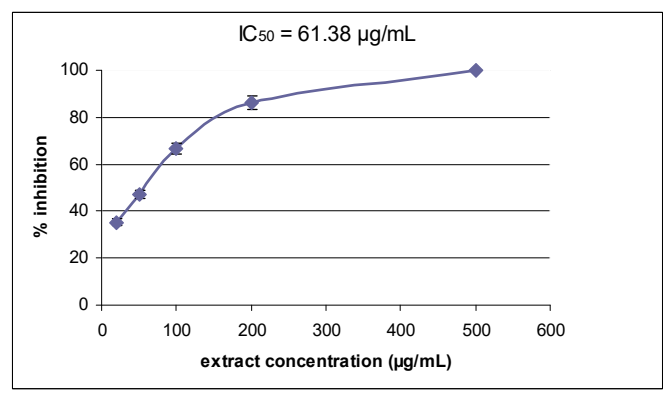

Figure 1. The inhibitory effect on advanced glycation end-products (AGE) formation of Scutellaria altissima shoot (A) and root (B) extracts and S. alpina shoot (C) and root (D) extracts at different concentrations. The results are mean values $\pm S E$. $\mathrm{IC}_{50}$, the concentration $(\mu \mathrm{g} / \mathrm{mL})$ required to reduce fluorescent AGE formation by $50 \%(n=4-5)$. 
Having identified the main metabolites present in the analyzed extracts, i.e., four flavonoids (baicalin, wogonoside, luteolin, luteolin-7-O- $\beta$-D-glucoside) and one phenylethanoid (verbascoside), the next stage was to evaluate their antiglycation capacity. Baicalin exhibited the highest antiglycation activity, followed by luteolin. The samples inhibited 90.4 and $85 \%$ of AGEs at a concentration of $100 \mu \mathrm{g} / \mathrm{mL}$ (Figure 2). Aminoguanidine, used as a positive control, gave only $75 \%$ inhibition, similar to the phenylethanoid verbascoside (71\%). Two other flavone glycosides (wogonoside and luteolin-7 glucoside) exhibited the lowest activity (about 50\%).

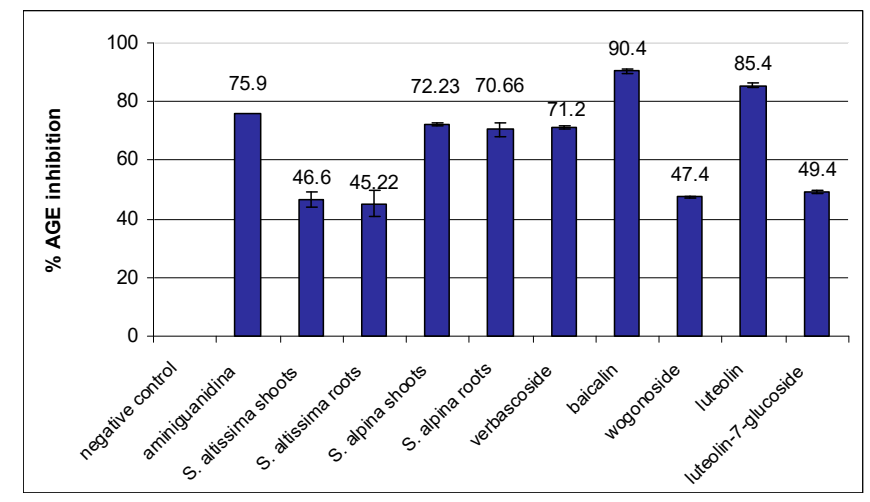

Figure 2. Antiglycation activity (expressed as \% inhibition of AGE formation) of S. altissima (shoot, root) extracts, S. alpina (shoot, root) extracts and the main compounds present in the analyzed extracts (verbascoside, baicalin, wogonoside, luteolin, luteolin-7-glucoside). BSA after glycation (100\% AGE) was used as the negative and aminoguanidine as the positive control. All extracts and compounds were used at a concentration of $100 \mu \mathrm{g} / \mathrm{mL}$. The results are the mean values $\pm \mathrm{SE}$.

A high correlation was observed between extract antiglycation activity and total flavonoid content (mg quercetin equivalents / g extract dry wt) $(\mathrm{r}=0.99)$ (Table 2). Lower, but also significant, was the relationship between the inhibitory effect of AGE formation and verbascoside level $(r=0.73)$. Moreover, the antiglycation effect was strongly correlated with the antioxidant potential of the analyzed plant extracts, as demonstrated by the reducing (FRAP) and inhibition of lipid peroxidation (LPO) assays ( $r=0.99$ and 0.93 , respectively). The antiradical test correlated slightly less with fluorescent AGE formation $(\mathrm{r}=0.88)$.

Table 2. Correlation coefficients between the antiglycation activity of S. altissima and S. alpina extracts (expressed as \% of inhibition of AGE formation) and antioxidant activity (in FRAP, DPPH and lipid peroxidation (LPO) assays), total content of flavonoid compounds and verbascoside content.

\begin{tabular}{cccccc}
\hline $\begin{array}{c}\text { Correlation } \\
\text { Coefficient (r) }\end{array}$ & $\begin{array}{c}\text { Flavonoid } \\
\text { Content }\end{array}$ & $\begin{array}{c}\text { Verbascoside } \\
\text { Content }\end{array}$ & FRAP & DPPH (EC 50 ) & $\begin{array}{c}\text { \% Inhibition } \\
\text { LPO }\end{array}$ \\
\hline $\begin{array}{c}\text { \% inhibition } \\
\text { AGE formation }\end{array}$ & 0.99 & 0.73 & 0.99 & -0.83 & 0.93 \\
Linear regression & $\mathrm{y}=2.05 \mathrm{x}+17.57$ & $\mathrm{y}=3.85 \mathrm{x}+44.92$ & $\mathrm{y}=0.08 \mathrm{x}+15.71$ & $\mathrm{y}=-0.79 \mathrm{x}+123.18$ & $\mathrm{y}=0.98 \mathrm{x}+14.72$ \\
\hline
\end{tabular}

\section{Discussion}

The results of the FRAP, DPPH and LPO assays revealed that all tested Scutellaria extracts have potent antioxidant activity. S. alpina extracts demonstrated similar $\mathrm{EC}_{50}$ values as Zingiber officinale $(75 \mu \mathrm{g} / \mathrm{mL})$, while S. altissima was comparable to Myristica fragrans $(100 \mu \mathrm{g} / \mathrm{mL})$ [16] and Camelia sinensis $(100 \mu \mathrm{g} / \mathrm{mL})$ [17].

The antioxidant properties of Scutellaria plants can be explained by the presence of different flavones and the phenylethanoid glycoside verbascoside, also known as acteoside. Both drugs from S. alpina are rich in flavonoids: they were found to contain about twice the amount as S. altissima 
(Table 1). A quantitative analysis of verbascoside present in extracts from the roots and shoots of S. altissima and S. alpina is given elsewhere [13]. This phenylethanoid glycoside was found in extracts from both analyzed Scutellaria species and was found in greater amounts in the roots than the shoots of both plants. Additionally, S. alpina accumulated higher verbascoside levels in both organs.

Numerous studies evaluating the antioxidant capacity of flavonoids have been published. The compounds have the ability to quench free radicals through the donation of electrons and hydrogen atoms, chelate transition metals or inhibit lipid peroxidation [18]. Verbascoside has also been shown to have antioxidant activity. It has been reported to display radical scavenging activity against diphenylpicrylhydrazyl (DPPH) and hydroxyl and superoxide anions [19].

In this study, BSA was chosen as the model protein for AGE formation. The intensity of fluorescence increased during the process of glycation, while the tested extracts and compounds suppressed this. The inhibitory effects of extracts from S. alpina and S. altissima plants were measured first. A representative antiglycation compound, aminoguanidine (AG), was used as a positive control. AG is known to prevent AGE formation by trapping intermediates at the initial glycation stages. However, its clinical use is limited by the presence of some side effects, such as drug resistance and hepatotoxicity [20]. All analyzed extracts exhibited good antiglycation ability, though S. alpina extracts showed higher potential $\left(\mathrm{IC}_{50}\right.$ about $\left.60 \mu \mathrm{g} / \mathrm{mL}\right)$ than aminoguanidine $(63 \mu \mathrm{g} / \mathrm{mL})$. The analyzed extracts displayed higher antiglycation activity than strawberry, blueberry or lemon fruit (IC $\mathrm{I}_{50}$ between $290-460 \mu \mathrm{g} / \mathrm{mL})$, although not as much as the peel of Punica granatum $(5 \mu \mathrm{g} / \mathrm{mL})$ or Garcinia mangostana $(40 \mu \mathrm{g} / \mathrm{mL})$ [21].

Glycation and AGE formation are associated with increased free radical production. Glycation is a major source of the reactive carbonyl and oxygen species generated by oxidative and non-oxidative pathways [22]. Inhibitors of AGE products may act not only as quenchers of dicarbonyl intermediates, but also as antioxidants or metal ion chelators. Therefore, compounds with antioxidant activity could also inhibit the formation of AGE. Nakagawa et al. [23] noted that green tea demonstrates strong antiglycation activity in addition to its known antioxidant potential. However, Chen et al. [24] describe plant extracts that possess strong antiglycation, but low antioxidant activity (Astragalus membranaceus), or strong antioxidant, but low antiglycation potential (Periploca sepium). Our present findings indicate a strong relationship between antioxidant properties and antiglycation activity $(r=0.89-0.99$, depending on the antioxidant test). Inhibition of AGE formation correlated more with FRAP and LPO than with DPPH scavenging, which likely reflects the greater involvement of the reduction and peroxidation prevention than direct radical scavenging in glycation reactions. In some berry species, a higher correlation was observed between the inhibition of AGE formation and oxygen radical absorbance capacity (ORAC) than with the DPPH assay [25].

The antioxidant properties of many plant extracts are generally attributed to their phenolic content [26,27]. Several independent studies have demonstrated that antiglycation properties significantly correlate with the concentration of these compounds [28]. For example, Dearlove et al. [29] observed a strong relationship between antiglycation activity and total phenolic content in twenty-four herbs and spices. However, Ramkissoon et al. [30] proposed that the antiglycation properties of plant extracts cannot always be attributed to their phenolic content or antioxidant potential. Firstly, other compounds present in the extracts have been reported to interfere in fluorescence measurements [1]. Such interference was also seen in our analysis, when the intensity of fluorescence was measured at an extract excitation wavelength of $370 \mathrm{~nm}$ and emission wavelength of $440 \mathrm{~nm}$. Secondly, the low correlation between antiglycation potential and polyphenol level may be associated with several possible mechanisms of activity, not only those associated with the antioxidant model, as confirmed by tests on quercetin and ascorbic acid. While quercetin exhibited both high antioxidant and antiglycation activities, vitamin $\mathrm{C}$ has no antiglycation ability, despite being a strong antioxidant [25].

All pure compounds tested in our study inhibited AGE formation, but their activity was significantly different. Baicalin and luteolin showed the greatest inhibitory effects. These two compounds were more effective glycation inhibitors than the reference drug aminoguanidine. It 
is known that the activity of flavonoids is strongly related to their structure. Studies on individual compounds reported by Matsuda et al. [31] provide structural determinants of both antiglycation and antioxidant activity. In particular, flavonoids with hydroxyl groups at the $3-^{\prime}, 4^{\prime}-, 5$ - and 7-positions showed a significant inhibitory activity against AGE in vitro. The activities of flavones were stronger than those of flavonols, flavanones or isoflavones. Furthermore, methylation or glucosylation of the 4'-hydroxyl group increased, but blocking of the 7-hydroxyl group reduced the antiglycation activity. The authors report a correlation between AGE inhibitory and scavenging activity. However, several conflicting observations were noted regarding antioxidant and antiglycation ability. For example, methylation of the 3-hydroxyl group enhanced the inhibitory effect concerning AGE formation, but reduced antiradical potential, as confirmed by the weaker activity demonstrated by 7-O-glucoside than aglycon luteolin observed in our study. Conversely, baicalin, which is also a 7-O-glycosylated (glucuronide) flavone with fewer hydroxyl groups, was stronger than luteolin. This is consistent with Matsuda et al. [31], who report that the baicalin aglycon, baicalein showed stronger inhibition than luteolin $(79 \%$ and $64 \%$, respectively, at a concentration of $200 \mu \mathrm{M}$, equivalent of roughly 54 and $57 \mu \mathrm{g} / \mathrm{mL}$ ). The pivotal role of the hydroxyl group number can be also questioned by the comparable efficiency of luteolin-7-O-glucoside and wogonoside, even though the latter compound has only one free $\mathrm{OH}$ group. Therefore, other structural features contribute to the final antiglycation activity besides the number of hydroxyl groups. A more thorough study of structure-activity relationships, including their quantitative and mechanistic aspects, is necessary to explain the conflicting experimental observations.

Besides the flavonoids, verbascoside also has an influence on the antiglycation activity of Scutellaria extracts. Its ability to inhibit AGE formation was close to that of aminoguanidine. However, the correlation between the antiglycation potential of the studied extracts and the level of verbascoside was not as strong as for flavonoids. In Brandisia hancei (Paulowniaceae), verbascoside (acteoside) was the main antiglycative compound. It was found to be five-times stronger than quercetin (a flavonol) in terms of molar $\mathrm{IC}_{50}(5.11 \mu \mathrm{M}$ vs. $28.41 \mu \mathrm{M})$, but only about 2.7 -times greater in terms of mass concentration units [32]. Beside glycation and aldose reductase inhibition, verbascoside was able to decrease glucose level and increase glucose tolerance in mice [33]. However, no previous study could be found that compared the activity of verbascoside to other flavones thought to be stronger than flavonols.

\section{Experimental Section}

\subsection{Plant Material}

Plants of both species were grown for two years in the Medicinal Plant Garden of the Department of Pharmacognosy at the Medical University of Lodz. The plants were identified by Dr. I. Grzegorczyk-Karolak, and the voucher specimens were deposited in the Department of Biology and Pharmaceutical Botany, Medical University of Lodz. The S. altissima seeds were provided by the Garden of Medicinal Plants in Wroclaw (Wroclaw, Poland), and those of S. alpina were provided by the Botanical Garden of Institute of Ecology and Botany in Vácrátót (Vácrátót, Hungary). The experiments used the roots and aerial parts of the plants harvested during flowering. The plant material was cut and freeze dried.

\subsection{Preparation of Extracts}

The lyophilized plant material ( $1 \mathrm{~g}$ ) was pre-extracted by maceration in chloroform overnight at room temperature. After filtration, the plant material was extracted three times with $30 \mathrm{~mL}$ methanol:water $(7: 3, v / v)$ for $15 \mathrm{~min}$ in an ultrasonic bath. The extracts were combined and evaporated under reduced pressure. 


\subsection{Chemicals}

Standard compounds were used in the study, such as baicalin provided by Sigma-Aldrich (Darmstadt, Germany), wogonoside by ChemFace, luteolin and luteolin-7-O-glucoside (cynaroside) by Roth and verbascoside by Phytoplan.

\subsection{Total Flavonoid Content}

The colorimetric evaluation of flavonoid content was performed according to Lamaison and Carnat [34]. The absorbance of the reaction mixture was measured at $415 \mathrm{~nm}$ (Beijing Rayleigh Corp., Beijing, China). Quantification was performed using a standard quercetin (Sigma-Aldrich) calibration curve. The results were expressed as quercetin equivalents (mg per gram of dry extract).

\subsection{DPPH Radical Scavenging Assay}

The radical scavenging activity of plant extracts against the 1,1-diphenyl-2-picrylhydrazyl free radical (DPPH) (Sigma-Aldrich) was determined spectrophotometrically as described by Weremczuk-Jeżyna et al. [35]. The results were expressed as $E_{50}(\mu \mathrm{g} / \mathrm{mL})$, calculated as the concentration of sample with $50 \%$ of maximum scavenging activity.

\subsection{FRAP Assay}

The FRAP assay was determined according to Pulido et al. [36]. The antioxidant activity was determined against a standard of known FRAP value, ferrous sulfate, calculated from a calibration curve with concentrations from 0-2000 $\mu \mathrm{M}$. The antioxidant activity was expressed in $\mu \mathrm{M}$ Fe(II)/g of dry extract.

\subsection{Linoleic Acid Peroxidation Inhibition}

Linoleic acid peroxidation (LPO) inhibition was determined by the TBARS test according to Choi et al. [37]. The ability of a sample to inhibit the oxidation of linoleic acid is measured by spectrophotometry at $532 \mathrm{~nm}$. The percentage of linoleic acid peroxidation inhibition was calculated using the following equation:

$$
\% \text { inhibition }=(\text { Abs control }- \text { Abs sample }- \text { Abs extract }) \times 100 /(\text { Abs control }- \text { Abs extract })
$$

where Abs control is the absorbance of reaction mixture containing methanol instead of an extract.

\subsection{Antiglycation Assay}

The glycation of BSA was performed according to Bhatwadekar and Ghole [38] with some modifications. Briefly, BSA $(1 \mathrm{mg} / \mathrm{mL})$ was incubated with $0.25 \mathrm{M}$ fructose and $0.25 \mathrm{M}$ glucose in $0.1 \mathrm{M}$ phosphate-buffered saline (PBS), pH 7.4, in darkness at $50{ }^{\circ} \mathrm{C}$ for four days. Before incubation, the solution of plant extracts or pure compounds (verbascoside, baicalin, wogonoside, luteolin, luteolin-7-glucoside or a reference glycation inhibitor, aminoguanidine) dissolved in 50\% DMSO was added to the mixtures. The formation of glycated BSA was determined using fluorescent intensity at an excitation wavelength of $335 \mathrm{~nm}$ and emission wavelength of $385 \mathrm{~nm}$. The percentage of AGEs inhibition was calculated using the following equation:

$$
\% \text { AGE inhibition }=(\text { F control }- \text { F control blank }) \times 100 /(\text { F extract }- \text { F extract blank })
$$

where (F control - F control blank) is the difference between the fluorescent intensity of BSA incubated with or without glucose and fructose and (F extract - F extract blank) is the difference between the fluorescent intensity of BSA and sugars incubated with or without plant extracts. 


\subsection{Statistical Analysis}

All results are presented as the average \pm standard error (SE). The results were analyzed using the Kruskal-Wallis test. The level of significance was set at 5\%. STATISTICA 10.0 (STATSoft, Krakow, Poland) software was used for calculations. Each series of antioxidant and antiglycation assays and flavonoid measurements was repeated two or three times, and each sample was measured in triplicate. $\mathrm{EC}_{50}, \mathrm{IC}_{50}$, correlation coefficients between the antiglycation assay and antioxidant assays, verbascoside and total flavonoid content were calculated using MS-Excel software.

\section{Conclusion}

Our study shows for the first time that extracts of Scutellaria alpina and S. altissima possess antiglycation activity in vitro. S. alpina root extracts had the highest inhibitory effect on AGE formation. Furthermore, the results from the FRAP, DPPH and LPO assays indicated the high antioxidant activity of S. altissima and S. alpina extracts. The antioxidant properties of these two Scutellaria species and flavonoids contained in the extracts are, at least in part, involved in the mechanisms of albumin glycation inhibition. Two flavones from Scutellaria, baicalin and luteolin, were highly effective in preventing AGE formation.

In conclusion, among other therapeutic applications, Scutellaria plants should be considered as sources of active compounds against glycation-associated complications in diabetes and some types of cancer, as well as offering anti-aging properties.

Supplementary Materials: The following are available online at www.mdpi.com/1420-3049/21/6/739/s1. Table S1: MS fragmentation of the investigated compounds (verbascoside, baicalin, wogonoside) by HPLC-ESI-MS/MS, Table S2: LC-MS/MS spectrum of luteolin and luteolin-7-glucoside.

Acknowledgments: This work was financially supported by the Department of Biology and Pharmaceutical Botany, Medical University of Lodz (Grant no. 503/3-012-01/503-31-001).

Author Contributions: I.G.-K. and A.M. designed the experiments. I.G.-K. obtained plant materials, prepared extracts, evaluated antioxidant activities, performed total flavonoid contents and analyzed the data. K.G. and J.G. evaluated antiglycation activity. I.G.-K. and H.W. wrote the paper. A.M. was responsible for the verification of the paper. All authors discussed the results and read and approved the final manuscript.

Conflicts of Interest: The authors declare no conflict of interest.

\section{References}

1. Séro, L.; Sanguinet, L.; Blanchard, P.; Dang, B.T.; Morel, S.; Richomme, P.; Seraphin, D.; Derbré, S. Tuning a 96-well microtiter plate fluorescence-based assay to identify AGE inhibitors in crude plant extracts. Molecules 2013, 18, 14320-14339. [CrossRef] [PubMed]

2. Fukami, K.; Yamagishi, S.; Ueda, S.; Okuda, S. Role of AGEs in diabetic nephropathy. Curr. Pharm. Des. 2008, 14, 946-952. [CrossRef] [PubMed]

3. Sugimoto, K.; Yasujima, M.; Yagihashi, S. Role of advanced glycation end products in diabetic neuropathy. Curr. Pharm. Des. 2008, 14, 953-961. [CrossRef] [PubMed]

4. Yamagishi, S.I.; Nakamura, K.; Matsui, T.; Ueda, S.; Noda, Y.; Imaizumi, T. Inhibitors of advanced glycation end products (AGEs): Potential utility for the treatment of cardiovascular disease. Cardiovasc. Ther. 2008, 26, 50-58. [CrossRef] [PubMed]

5. Kaushik, G.; Satya, S.; Khandelwal, R.K.; Naik, S.N. Commonly consumed Indian plant food materials in the management of diabetes mellitus. Diabetes Metab. Syndr. Clin. Res. Rev. 2010, 4, 21-40. [CrossRef]

6. Jung, H.A.; Kim, Y.S.; Choi, J.S. Quantitative HPLC analysis of two key flavonoids and inhibitory activities against aldose reductase from different parts of the Korean thistle, Cirsium maackii. Food Chem. Toxicol. 2009, 47, 2790-2797. [CrossRef] [PubMed]

7. Tsuji-Naito, K.; Saeki, H.; Hamano, M. Inhibitory effects of Chrysanthemum species extracts on formation of advanced glycation end products. Food Chem. 2009, 116, 854-859. [CrossRef]

8. Reddy, V.P.; Beyaz, A. Inhibitors of the Maillard reaction and AGE breakers as therapeutics for multiple diseases. Drug Discov. Today 2006, 11, 646-654. [CrossRef] [PubMed] 
9. McDougall, G.J.; Shapiro, F.; Dobson, P.; Smith, P.; Blake, A.; Stewart, D. Different polyphenolic components of soft fruits inhibit $\alpha$-amylase and $\alpha$-glucosidase. J. Agr. Food Chem. 2005, 53, 2760-2766. [CrossRef] [PubMed]

10. Pinto, M.D.S.; Kwon, Y.I.; Apostolidis, E.; Lajolo, F.M.; Genovese, M.I.; Shetty, K. Potential of Ginkgo biloba L. leaves in the management of hyperglycemia and hypertension using in vitro models. Bioresource Technol. 2009, 100, 6599-6609. [CrossRef] [PubMed]

11. Shang, X.; He, X.; He, X.; Li, M.; Zhang, R.; Fan, P.; Zhang, Q.; Jia, Z. The genus Scutellaria an ethnopharmacological and phytochemical review. J. Ethnopharmacol. 2010, 128, 279-313. [CrossRef] [PubMed]

12. Hou, G.Y.; Wang, L.; Liu, S.; Song, F.R.; Liu, Z.Q. Inhibitory effect of eleven herbal extracts on advanced glycation end-products formation and aldose reductase activity. Chinese Chem. Lett. 2014, 25, 1039-1043. [CrossRef]

13. Grzegorczyk-Karolak, I.; Wysokińska, H.; Olas, B. Studies on the antioxidant properties of extracts from the roots and shoots of two Scutellaria species in human blood plasma. Acta. Biochim. Pol. 2015, 62, 253-258. [CrossRef] [PubMed]

14. Grzegorczyk-Karolak, I.; Kuźma, Ł.; Wysokińska, H. The use of long-term Scutellaria altissima callus cultures for shoot regeneration, production of bioactive metabolites and micropropagation. J. Med. Plants Res. 2013, 7, 3003-3313.

15. Grzegorczyk-Karolak, I.; Kuźma, Ł.; Wysokińska, H. Study on the chemical composition and antioxidant activity of extracts from shoot culture and regenerated plants of Scutellaria altissima L. Acta. Physiol. Plant 2015, 37, 1736-1744. [CrossRef]

16. Kazeem, M.I.; Akanji, M.A.; Hafizur, R.M.; Choudhary, M.I. Antiglycation, antioxidant and toxicological potential of polyphenol extracts of alligator pepper, ginger and nutmeg from Nigeria. Asian Pac. J. Trop. Biomem. 2012, 2, 727-732. [CrossRef]

17. Povichit, N.; Phrutivorapongkul, A.; Suttajit, M.; Chaiyasut, C.; Leelapornpisid, P. Phenolic content and in vitro inhibitory effects on oxidation and protein glycation of some Thai medicinal plants. Pak. J. Pharm. Sci. 2010, 23, 403-408. [PubMed]

18. Procházková, D.; Boušová, I.; Wilhelmová, N. Antioxidant and prooxidant properties of flavonoids. Fitoterapia 2011, 82, 513-523. [CrossRef] [PubMed]

19. Kyriakopoulou, I.; Magiatis, P.; Skaltsounis, A.L.; Aligiannis, N.; Harvala, C. Samioside, a new phenylethanoid glycoside with free-radical scavenging and antimicrobial activities from Phlomis samia. J. Nat. Prod. 2001, 64, 1095-1097. [CrossRef] [PubMed]

20. Thornalley, P.J. Use of aminoguanidine (Pimagedine) to prevent the formation of advanced glycation endproducts. Arch. Biochem. Biophys. 2003, 419, 31-40. [CrossRef] [PubMed]

21. Parengkuan, L.; Yagi, M.; Matsushima, M.; Ogura, M.; Hamada, U.; Yonei, Y. Anti-glycation activity of various fruits. Anti-Aging Med. 2013, 10, 70-76.

22. Rahbar, S.; Figarola, J.L. Novel inhibitors of advanced glycation endproducts. Arch. Biochem. Biophys. 2003, 419, 63-79. [CrossRef]

23. Nakagawa, T.; Yokozawa, T.; Terasawa, K.; Shu, S.; Juneja, L.R. Protective activity of green tea against free radical-and glucose-mediated protein damage. J. Agr. Food Chem. 2002, 50, 2418-2422. [CrossRef]

24. Chen, Y.F.; Roan, H.Y.; Li, C.K.; Huang, Y.C.; Wang, T.S. Relationship between antioxidant and antiglycation ability of saponins, polyphenols, and polysaccharides in Chinese herbal medicines used to treat diabetes. J. Med. Plants Res. 2011, 5, 2322-2331.

25. Harris, C.S.; Cuerrier, A.; Lamont, E.; Haddad, P.S.; Arnason, J.T.; Bennett, S.A.; Johns, T. Investigating wild berries as a dietary approach to reducing the formation of advanced glycation endproducts: Chemical correlates of in vitro antiglycation activity. Plant Foods Hum. Nutr. 2014, 69, 71-77. [CrossRef] [PubMed]

26. Grzegorczyk, I.; Matkowski, A.; Wysokińska, H. Antioxidant activity of extracts from in vitro cultures of Salvia officinalis L. Food Chem. 2007, 104, 536-541. [CrossRef]

27. Rice-Evans, C.; Miller, N.; Paganga, G. Antioxidant properties of phenolic compounds. Trends Plant Sci. 1997, 2, 152-159. [CrossRef]

28. Wu, C.H.; Yen, G.C. Inhibitory effect of naturally occurring flavonoids on the formation of advanced glycation endproducts. J. Agr. Food Chem. 2005, 53, 3167-3173. [CrossRef] [PubMed] 
29. Dearlove, R.P.; Greenspan, P.; Hartle, D.K.; Swanson, R.B.; Hargrove, J.L. Inhibition of protein glycation by extracts of culinary herbs and spices. J. Med. Food 2008, 11, 275-281. [CrossRef] [PubMed]

30. Ramkissoon, J.S.; Mahomoodally, M.F.; Ahmed, N.; Subratty, A.H. Relationship between total phenolic content, antioxidant potential, and antiglycation abilities of common culinary herbs and spices. J. Med. Food 2012, 15, 1116-1123. [CrossRef] [PubMed]

31. Matsuda, H.; Wang, T.; Managi, H.; Yoshikawa, M. Structural requirements of flavonoids for inhibition of protein glycation and radical scavenging activities. Bioorgan. Med. Chem. 2003, 11, 5317-5323. [CrossRef]

32. Yu, S.Y.; Lee, I.S.; Jung, S.H.; Lee, Y.M.; Lee, Y.R.; Kim, J.H.; Sun, H.; Kim, J.S. Caffeoylated phenylpropanoid glycosides from Brandisia hancei inhibit advanced glycation end product formation and aldose reductase in vitro and vessel dilation in larval zebrafish in vivo. Planta Med. 2013, 79, 1705-1709. [CrossRef] [PubMed]

33. Morikawa, T.; Ninomiya, K.; Imamura, M.; Akaki, J.; Fujikura, S.; Pan, Y.; Yuan, D.; Yoshikawa, M.; Jia, X.; Li, Z.; et al. Acylated phenylethanoid glycosides, echinacoside and acteoside from Cistanche tubulosa, improve glucose tolerance in mice. J. Nat. Med. 2014, 68, 561-566. [CrossRef] [PubMed]

34. Lamaison, J.L.; Carnat, A. Levels of principal flavonoids in flowers and leaves of Crataegus monogyna Jacq and Crataegus laevigata (Poiret) Dc (Rosaceae). Pharm. Acta Helv. 1990, 65, 315-320.

35. Weremczuk-Jeżyna, I.; Grzegorczyk-Karolak, I.; Frydrych, B.; Królicka, A.; Wysokińska, H. Hairy roots of Dracocephalum moldavica: Rosmarinic acid content and antioxidant potential. Acta. Physiol. Plant 2013, 35, 2095-2103. [CrossRef]

36. Pulido, R.; Bravo, L.; Saura-Calixto, F. Antioxidant activity of dietary polyphenols as determined by a modified ferric reducing/antioxidant power assay. J. Agr. Food Chem. 2000, 48, 3396-3402. [CrossRef]

37. Choi, C.W.; Kim, S.C.; Hwang, S.S.; Choi, B.K.; Ahn, H.J.; Lee, M.Y.; Park, S.H.; Kim, S.K. Antioxidant activity and free radical scavenging capacity between Korean medicinal plants and flavonoids by assay-guided comparison. Plant Sci. 2002, 163, 1161-1168. [CrossRef]

38. Bhatwadekar, A.D.; Ghole, V.S. Rapid method for the preparation of an AGE-BSA standard calibrator using thermal glycation. J. Clin. Lab. Anal. 2005, 19, 11-15. [CrossRef] [PubMed]

Sample Availability: Samples of the compounds are available from the authors.

(C) 2016 by the authors; licensee MDPI, Basel, Switzerland. This article is an open access article distributed under the terms and conditions of the Creative Commons Attribution (CC-BY) license (http://creativecommons.org/licenses/by/4.0/). 